\title{
METODOLOGÍA PARA LA CAPACITACIÓN DOCENTE EN HERRAMIENTAS TECNOLÓGICAS COMO MEDIACIÓN EN EL TRÁNSITO DE LO PRESENCIAL A LO REMOTO
}

Fredy Ramón Garay Garay*, Yenny Paola Sierra Bonilla** Angie Rocío Melo Casas ${ }^{* * *}$, John Fredy Morales García****

\section{Introducción}

La pandemia generada por el COVID-19 (coronavirus disease 2019), cuyo origen fue determinado en la ciudad de Wuhan, China, en el año 2019, ha logrado confinar a la población mundial y modificar las dinámicas actuales de todas y cada una de las actividades humanas, debido a que ha tenido un impacto total y directo sobre el comercio, la industria, la banca, la salud y la educación en el mundo.

* Doctor en Enseñanza, Filosofía e Historia de las Ciencias. Director del Departamento de Ciencias Básicas de la Universidad Católica de Colombia. https://orcid.org/0000-0001-7158-0784

* Magíster en Educación de la Universidad Minuto de Dios. Especialista en Estadística de la Universidad Nacional de Colombia. Profesional en Matemáticas y Estadística de la Universidad del Tolima. https://orcid.org/0000-0002-3820-6114

* Magíster en Ciencias Matemáticas de la Universidad Nacional de Colombia, Matemática de la Universidad Distrital. https://orcid.org/0000-0001-8855-7855

**** MSc. en Educación Matemática. Profesor Universitario con más de 15 años de experiencia https://orcid.org/0000-0003-4752-7101 
Esta última, la educación, al igual que las demás áreas, se vio obligada a transformarse, adaptarse y evolucionar en la inmediatez de la exigencia social originada por la pandemia, decretada por la oms a finales de 2019 y atendida de inmediato por los gobiernos locales, nacionales e internacionales. La medida dictaminada inicialmente - la suspensión de clases presenciales - fue definitiva para la educación, pero esta no supuso que el sistema educativo dejara de funcionar o hiciera un alto en sus actividades; todo lo contrario, se tuvo que encontrar caminos alternativos para continuar con la formación de niños, jóvenes y adultos en todos los niveles educativos, aunque para ello se tuvo que reconocer que no estábamos preparados para esto. Como afirma Giannini (2020):

Para ser francos, debemos reconocer que no estábamos preparados para una disrupción a semejante escala. Casi de la noche a la mañana, las escuelas y universidades de todo el mundo cerraron sus puertas, afectando a 1.570 millones de estudiantes en 191 países [...] (p. 5)

Para hacer frente a este desafío global, las clases remotas se convirtieron en la mejor manera para continuar con los procesos de formación en el marco del sistema educativo mundial, nacional y regional, gracias a que se tenía la experiencia acumulada tanto desde la práctica como desde la investigación en educación virtual, todo lo cual permitió un tránsito difícil, pero eficiente, de las clases presenciales a las clases remotas mediadas por tecnología.

Debido a esto, emerge entonces el gran interrogante en torno a si los docentes estaban o no preparados para afrontar este nuevo reto y hacer la transición de lo presencial a lo remoto en la inmediatez de la exigencia global.

Apuntando a una respuesta a este interrogante, como elemento contextual se puede afirmar que en las últimas décadas algunas actividades paralelas al sistema educativo - como las científicas y tecnológicas - habían evolucionado a pasos agigantados en todo el mundo. Mientras los límites de la ciencia son empujados a diario por cientos de investigadores — protagonistas del proceso de construcción del conocimiento científico-, los avances técnicos y tecnológicos han provisto a las sociedades actuales de equipamientos, artefactos y herramientas - entre ellas las digitales - que han mejorado la calidad de vida en diferentes aspectos y que han buscado optimizar el accionar de la educación en diversos niveles. No obstante, esto conlleva a un nuevo interrogante respecto a si la práctica docente - en particular en el contexto colombiano- a nivel de las Instituciones de Educación Superior (IES) había evolucionado a la par de la ciencia y la tecnología.

En investigaciones como la de Garritz (2010) se afirma que no es la primera vez que se habla de cambios acelerados y de la necesidad de modernizar la educación; de hecho, en ellas es posible evidenciar que el sistema educativo parece haber quedado anclado a prácticas pedagógicas y didácticas propias del siglo anterior. En este sentido, el obligante cambio de 
modalidad de lo presencial a lo remoto para el desarrollo de las sesiones de clase mostró la necesidad de actualizar al personal docente en el uso de herramientas tecnológicas con el fin de mejorar sus prácticas educativas y con ello tener la posibilidad de continuar con su ejercicio profesional docente.

Partiendo de este escenario, el presente capítulo se enfoca en el diseño y validación de una metodología de capacitación de profesores para el uso de herramientas tecnológicas que les permitieran continuar con su quehacer profesional durante el periodo de pandemia.

Para ello, se presenta y socializa el proceso tanto de construcción como de ejecución y retroalimentación de la metodología usada por el Departamento de Ciencias Básicas de la Universidad Católica de Colombia, no solo a manera de divulgación, sino también como forma de validar esta buena práctica y con el fin de que pueda ser usada en otros contextos de formación de profesores.

Uno de los resultados que se destaca en el presente texto respecto a la implementación de la metodología de capacitación está directamente relacionado con la articulación de espacios interculturales en las sesiones de clase remotas mediadas por las Tecnologías de la Información y Comunicación (TIC), pues tanto ingenieros como economistas en formación tuvieron la oportunidad de intercambiar experiencias con pares de países como Argentina y México, con lo cual es posible reconocer también los valores agregados de la metodología propuesta.

\section{Elementos teóricos que aportaron a la construcción}

En el diseño y ejecución de la metodología se tuvieron en cuenta diferentes perspectivas teóricas que se convirtieron en la base estructural de esta propuesta, pues en su consolidación fueron pilares tanto lo establecido por el Ministerio de Educación Nacional (MEN) respecto al perfil del docente universitario de ciencias básicas como el vasto universo de la literatura frente a la inclusión de las herramientas y recursos tecnológicos al sistema educativo.

Inicialmente, en el artículo 5 del decreto 1278 de 2002, el men establece en su definición del ser docente que:

Las personas que desarrollan labores académicas directa y personalmente con los alumnos de los establecimientos educativos en su proceso enseñanza aprendizaje se denominan docentes. Estos también son responsables de las actividades curriculares no lectivas complementarias de la función docente de aula, entendidas como administración del proceso educativo, preparación de su tarea académica, investigación de asuntos pedagógicos, evaluación, 
calificación, planeación, disciplina y formación de los alumnos, reuniones de profesores, dirección de grupo, actividades formativas, culturales y deportivas, atención a los padres de familia y acudientes, servicio de orientación estudiantil y actividades vinculadas con organismos o instituciones del sector que incidan directa o indirectamente en la educación. (art. 5)

De esta forma, se establece una definición general que supone lineamientos amplios para todos aquellos que deciden, por diferentes razones, ejercer esta profesión - aun sin formase en ella-, y obliga a que estos cumplan con una serie de habilidades, competencias, funciones y actividades propias del quehacer profesional docente. No obstante, esta definición no es clara frente a la formación en competencias y herramientas técnicas y tecnológicas que posibiliten elementos de mejora u optimización tanto de la labor docente como de la educación.

Teniendo esto en cuenta, y sumado a las evidentes deficiencias en el desarrollo profesional en la educación superior, la propuesta de Garay y Mejía (2020) busca establecer un perfil profesional para los docentes de ciencias básicas a nivel universitario. En su trabajo, los autores discuten la importancia de revisar las habilidades y capacidades que estructuran el quehacer del docente universitario, y a partir de ello buscan determinar las competencias que abarcan no solo los elementos profesionales, sino también los metodológicos y operacionales que puedan hacer frente a los distintos fenómenos relevantes en este nivel educacional, incluidos, entre otros, la deserción universitaria y la pérdida de las asignaturas del componente básico de formación profesional —física, química, estadística, matemáticas-. Con esto, se busca que la nueva modalidad de clases remotas se desarrolle con un estándar de calidad alto y coherente con las exigencias del sistema educativo, lo cual obliga al desarrollo de habilidades digitales por parte de los profesores.

De este modo, en la propuesta de Garay y Mejía (2020) se identifican las competencias digitales como transversales al quehacer del profesor universitario de ciencias básicas, razón por la cual es deber de las instituciones de formación de profesores - y de las instituciones educativas que contratan profesionales sin formación profesoral- garantizar el proceso de capacitación en estas competencias. Con esto, se garantiza un profesional no solo cualificado, sino también actualizado y capacitado en el uso de herramientas tecnológicas y digitales sólidas, y, por tanto, capaz de asumir los retos demandantes de un sistema educativo dinámico y globalizado.

\section{Metodología de capacitación docente IFAS}

La rapidez con que la situación de la pandemia se precipitó, que incluso llevó a la suspensión de las clases presenciales — pero no a un paro de actividades del sistema educativo—, obligó a las instituciones de educación en todos los niveles a diseñar y proyectar veloz y eficientemente acciones y estrategias para superar los retos y desafíos planteados por este nuevo escenario; y para ello, se partió de las herramientas y recursos con los que ya se contaba para el desarrollo de algunas actividades de forma virtual. 
Desde el año 2008, la unESCo estableció los estándares de competencia en Tic para docentes, y los estructuró a partir de tres enfoques que impactan en los diferentes componentes del sistema educativo: (a) la adquisición de nociones básicas de TIC, (b) la profundización del conocimiento, y (c) la generación de conocimiento. En lo que respecta a la formación profesional del docente, estos tres enfoques hacen referencia a: primero, el alfabetismo en las TIC; segundo, la gestión y guía en el uso de las Tic; y, tercero, el docente modelo de educando (UNESCO, 2008).

Como antecedentes, y atendiendo al enfoque del alfabetismo en las TIC —adquisición de nociones básicas respecto a las Tic-, en el caso del Departamento de Ciencias Básicas de la Universidad Católica de Colombia, un compendio de experiencias previas se convirtió en el punto de partida para programar las actividades que configuraron y estructuraron una metodología de identificación, formación, adecuación y seguimiento — de allí el nombre de la metodología: IFAS-.

En el Departamento de Ciencias Básicas, cada profesor que ingresa a carrera docente debe realizar un proceso de capacitación profesoral en recursos tic en el que aprende a usar, por ejemplo, la plataforma Moodle —donde se alojan las Aulas Virtuales de Aprendizaje (AVA)—, una plataforma protagonista en los procesos de evaluación, socialización, apropiación, interacción y adecuación de la información. Adicional a esto, antes de la pandemia algunas asignaturas ofrecidas por el departamento contaban con laboratorios y actividades prácticas que involucraban el uso de programas como SPSS, GeoGebra, Mathematica, entre otros. $\mathrm{E}$, incluso, desde antes se buscaba el uso de los recursos digitales en las clases presenciales como una forma de promover una cultura de la transformación de las prácticas tradicionales de enseñanza.

Otra de las actividades del Departamento que exigía una formación en TIC antes de la pandemia era el programa de Tutorías Virtuales — diseñado, implementado y desarrollado durante los últimos cinco años-, y este fue uno de los elementos que más aportó al proceso de adaptación, sobre todo por la experiencia y el conocimiento que tenía frente a la ejecución de actividades académicas en plataformas de comunicación remota en tiempo real -como Zoom, Vc Express, Google Meet, entre otros-.

Ahora bien, a partir de estos antecedentes como base robusta, la metodología IFAS se formuló por medio de cuatro etapas fundamentales para el proceso de formación docente en herramientas tecnológicas, lo cual facilitó el tránsito de lo presencial a lo remoto, y a su vez garantizó el cumplimiento de los objetivos de formación en ciencias básicas de los futuros profesionales en las carreras de Ingeniería, Economía y Psicología, entre otras. Estas cuatro etapas consistieron en: (a) identificación, (b) formación, (c) adecuación, y (d) seguimiento. 


\section{Identificación}

Respecto a las competencias digitales —el manejo de las TIC-, los elementos mencionados configuraron los parámetros que hicieron posible la caracterización del equipo docente del Departamento de Ciencias Básicas de la Universidad Católica de Colombia. A partir de las competencias digitales ya identificadas antes de la pandemia, para el planteamiento de la metodología se indagó sobre el dominio o experticia —alfabetismo de Tic- de los docentes en tres aspectos: (a) el conocimiento respecto a las Aulas Virtuales de Aprendizaje (AVA) — espacios de adecuación, apropiación, repositorio de información y evaluación-; (b) el conocimiento respecto a las herramientas de software de apoyo a las sesiones de clase - con programas como Geogebra, Mathematica, Symbolab, PQRS, Probability Distributions, entre otros-; y (c) el conocimiento respecto al medio de comunicación remota sincrónica -en nuestro caso, a partir del programa Cisco Webex-.

Este proceso de identificación y caracterización del cuerpo profesoral permitió reconocer tanto sus fortalezas como las oportunidades de mejora, lo que posibilitó el diseño y validación de una propuesta de capacitación docente para hacer frente a la nueva dinámica educacional en medio de una pandemia.

\section{Formación}

Con los resultados obtenidos en la fase anterior, se estableció que esta nueva etapa no se podía estipular como un espacio de formación especializado centrado en las habilidades técnicas de los docentes, sino que, en su lugar, se debía formular proporcionando una capacitación centrada en conocimientos específicos y pragmáticos con el fin de garantizar la continuidad del ejercicio profesional. No podemos olvidar que la estrategia respondía a una medida de contingencia ante la apremiante situación, más que a un proceso de educación continuada del cuerpo docente.

En este punto, es de resaltar que la universidad ofertó múltiples capacitaciones de forma transversal para todos los profesores, y que estas atendían a las habilidades digitales discriminadas en la fase de identificación. En particular, las capacitaciones incluyeron el manejo de las plataformas Moodle y Cisco Webex, el diseño de material de apoyo para sesiones de clase, y las estrategias de evaluación en medios virtuales.

Adicionalmente, el Departamento de Ciencias Básicas ofreció orientaciones respecto al uso de herramientas sugeridas para un desarrollo óptimo de los encuentros sincrónicos mediados por tecnología con los estudiantes —en las cuales se incluía, por ejemplo, el uso de tableros digitales-, donde se enseñaba respecto a las características de los programas que se podían incluir en las clases remotas con el fin de potenciar el uso de recursos digitales que no estaban 
disponibles para todos los estudiantes en tiempo real en las sesiones presenciales. En esta misma línea, en los casos necesarios, se ofrecieron capacitaciones respecto al manejo de simuladores virtuales de laboratorios de física y química.

Estas capacitaciones se hicieron de manera sincrónica remota, y estuvieron a cargo de los profesores expertos. Específicamente, se realizaron cinco sesiones, dos refuerzos, y se creó un equipo técnico con los docentes que obtuvieron una puntuación "muy superior" en la etapa anterior, con el fin de acompañar a los demás docentes en el proceso de adecuación en concordancia con el enfoque de "profundización del conocimiento" establecido en los estándares de competencias TIC para docentes (UNESCO, 2008).

\section{Adecuación}

Terminadas las etapas de identificación y formación, se procedió a llevar los conocimientos y destrezas adquiridas en las sesiones de formación y entrenamiento a un componente práctico, enfocado en la adaptación de las Aulas Virtuales de Aprendizaje (AVA).

Las AVA, en general, son consideradas entornos digitales que apoyan el proceso de enseñanza y aprendizaje, ya que tienen como base aplicaciones multimedia que favorecen la comunicación, interacción, mediación y participación entre docentes y estudiantes, y porque a partir de su uso se incentiva el aprendizaje colaborativo, el trabajo en equipo, la socialización sincrónica y el dinamismo en entornos remotos de aprendizaje.

De hecho, el dinamismo educacional de las AVA está enmarcado dentro de lo establecido por Barbera y Abadía (2005):

este tipo de actividad de enseñanza y aprendizaje virtual tiene como objetivo potenciar la actividad autónoma del estudiante poniendo a su disposición un conjunto de recursos de diferentes tipos con funciones educativas diferentes que deben serle útiles para su aprendizaje [...]. (p. 6)

Ahora bien, un factor determinante fue la adaptabilidad a la que el docente tuvo que hacer frente, debido a que a partir la situación se encontró con diferentes herramientas digitales que buscaban facilitar y mediar los procesos de enseñanza aprendizaje, y porque tuvo que asumir la necesidad de las TIC como apoyo en las diferentes estrategias didácticas creadas por el profesor, quien, además, debía adaptarse a un nuevo rol de innovador y contribuir para fortalecer los diferentes estilos aprendizaje —autónomo, colaborativo, cooperativo y significativo- del estudiante. 
De este modo, el docente se tuvo que enfrentar a la implementación de plataformas de comunicación sincrónica que le permitieron llevar a cabo las clases remotas y, por tanto, explorar diferentes herramientas, como ocurría al momento de compartir presentaciones, crear salas privadas, programar las clases, compartir audio y video, usar blogs, implementar cuestionarios, escribir por medio de chat, entre otros.

Adicional a esto, los docentes sintieron la necesidad de aprender a manipular herramientas digitales como los tableros que se encuentran en la web, las páginas para evaluación y conteo estadístico, las plataformas para infografías, y tantos otros recursos. Para ello, el correo institucional, así como el mecanismo de mensajería del AVA, se convirtieron en canales de comunicación imprescindibles no solo para los estudiantes, sino también para los docentes.

Por otra parte, así como el canal y la forma de impartir la clase tuvieron una transformación, los métodos de evaluación también fueron revaluados. Según García-Peñalvo et al. (2020), estos ahora debían: "orientarse a los resultados de aprendizaje, seguido del objeto de evaluación [...] y también enfocarse en los productos o evidencias, las tareas de evaluación, así como los criterios, técnicas e instrumentos" (p. 4).

Asimismo, la perspectiva de la evaluación había cambiado y los instrumentos para llevarla a cabo sufrieron un proceso adaptativo, ya que se debían considerar los productos y los procesos. Así, según García-Peñalvo et al. (2020):

El objeto de la evaluación puede ser un producto, cuando se parte de la idea de la transmisión del conocimiento del profesorado al estudiantado, pero cuando se pone más énfasis en las competencias, el proceso es un objeto más adecuado para su evaluación, aunque siempre es más complejo evaluar cómo se ha llevado a cabo una tarea que evaluar el resultado final de una tarea. (p. 5)

A la luz de estas características, instrumentos como los cuestionarios y bancos de preguntas ofrecieron una posibilidad de realizar las actividades evaluativas, ya que estos permiten validar conceptos, hechos y procedimientos matemáticos, así como evaluar un gran número de estudiantes de forma rápida (García-Peñalvo et al., 2020). Los bancos de preguntas con los que se contaba fueron puestos a prueba, validados, depurados y, sobre todo, robustecidos. Este fue un componente fundamental en la fase de adecuación de esta metodología.

\section{Seguimiento}

La familiarización con los nuevos contextos y ambientes académicos apoyados por tecnologías de la información no fue un proceso natural, principalmente por la pérdida del contacto humano entre los docentes y sus estudiantes, lo que se suma al proceso de largas e intensas 
horas empleadas en capacitaciones en habilidades que no son de uso cotidiano en su práctica habitual, así como en el diseño y construcción de material académico y de apoyo, y, sobre todo, en el desarrollo de clases en plataformas con diversas herramientas.

La explotación de todos estos nuevos recursos que ahora tenían a disposición no resultó ser un proceso sencillo, y junto con la premura de la necesidad de la ejecución de sus sesiones de clase, el cuerpo docente atravesó un cambio de paradigma hacia un nuevo modo de ejercer su labor, en una situación que, por una parte, da la sensación de una deshumanización en los procesos de enseñanza, pero que, por otra, también abre nuevos horizontes de posibilidades.

En esta nueva dinámica, es apenas natural que los inconvenientes se presentaran en las primeras sesiones de clases, aun cuando se habían realizado múltiples ensayos y pilotajes; las fallas de las plataformas, los recursos y el personal fueron elementos propios del proceso de adaptación y de las curvas de aprendizaje en el uso de las nuevas plataformas tanto de maestros como de estudiantes. En esta situación, un agente fundamental fue el Equipo de apoyo y seguimiento: un grupo de docentes con experiencias previas en diferentes aspectos que ahora son indispensables, con disposición y calificación suficiente para intervenir en situaciones en las que sus colegas necesitaban asesoría técnica o logística para el desarrollo de las sesiones remotas.

Este elemento de acompañamiento robusteció todo el proceso del desempeño docente en esta nueva modalidad, gracias a que ofreció a los profesores un espacio de apoyo, soporte y fortalecimiento de sus nuevas habilidades, y porque, al mismo tiempo, constituyó una estrategia sinérgica de enseñanza entre la experiencia académica y las herramientas y facilidades que el nuevo contexto virtual ofrece, que permitió optimizar la enseñanza de conceptos que ahora podían avocarse en elementos prácticos propios de la formación profesional de cada programa y asignatura ofrecida.

Por su parte, el ente organizacional académico interno del Departamento —el Comité Curricular - se encargó de las orientaciones y seguimiento a la renovación del enfoque de las sesiones remotas de clase, sacando partido de las facilidades que las nuevas herramientas ofrecen en el estudio disciplinar tanto del "para qué" como del "qué" en las asignaturas; esta nueva perspectiva, en el accidentado contexto, se presenta como una oportunidad de potenciar los resultados de aprendizaje de los estudiantes.

Establecidas las cuatro etapas de la metodología IFAS-CB — que se sintetizan en la Figura 1-, se procedió al desarrollo de las clases sincrónicas remotas mediadas por tecnología.

Es importante aclarar que para este proceso se contó con apenas una semana para el desarrollo de la metodología de capacitación, y que de ello radicó la importancia de tener un 
equipo de apoyo técnico, pues éramos conscientes de que se presentarían problemas que debían ser solucionados inmediatamente, además de que sabíamos que nos enfrentaríamos a escenarios donde no tendríamos el control de situaciones externas, como la conexión a internet, el servicio de luz, suficientes equipos en casa para la asistencia a clases, etc.

Figura 1: Experiencias exitosas en clases remotas. El caso del departamento de Ciencias Básicas de la Universidad Católica de Colombia

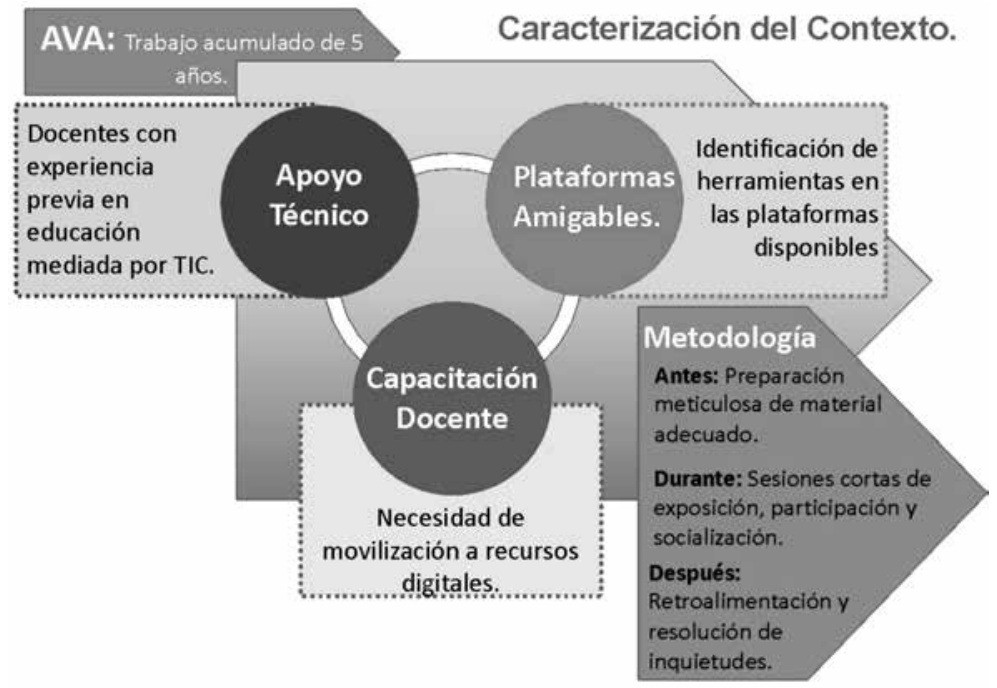

Nota. Tomado de Garay \& Mejía (2020)ํ․

Finalmente, hay mencionar que durante el desarrollo de las sesiones de clase remota, y como una forma de evaluar y retroalimentar el proceso llevado a cabo con la metodología IFAS-CB, se diseñó un instrumento de percepción que se aplicó tanto a estudiantes como a profesores del departamento. En particular, el instrumento, que fue sometido a revisión y validación por jueces expertos, estaba conformado por 10 ítems medidos en una escala tipo Likert de cinco puntos -1 = "Nunca", 2 = "Algunas veces", 3 = "Casi siempre" y 4 = "Siempre"—que buscaban medir la percepción de estudiantes y docentes del departamento respecto a las diferentes actividades realizadas en las clases remotas. La recolección de información inició inmediatamente después de la semana de alistamiento, de manera que para el 24 de abril de

1 Este trabajo fue presentado en el evento Compartiendo experiencias de enseñanza remota de las Ciencias, organizado por la Asociación Colombiana de Facultades de Ciencias (acofacien) en mayo de 2020. www.acofacien.org 
2020 se tenían 397 registros, con los cuales se obtuvo un alfa de Cronbach de 0.825 para la prueba, lo que indica una buena consistencia interna del instrumento (Oviedo \& Campo, 2005).

\section{Resultados preliminares}

Para evaluar la implementación de la metodología IFAS-CB, primero se realizó el análisis —por medio del software estadístico SPSS, versión 26- de los datos obtenidos tras la aplicación del instrumento en los estudiantes, y en las preguntas iniciales, con las cuales se procedió a realizar la caracterización de la muestra, se evidenció que el $49.87 \%$ de los estudiantes encuestados correspondía a la jornada diurna y el $50.3 \%$ a la jornada nocturna (véase Figura 2); y que el $74.31 \%$ pertenecía a la Facultad de Ingeniería, el $9.32 \%$ a la Facultad de Economía, el 8.06 \% a la Facultad de Psicología, el 7.56 \% a la Facultad de Derecho, el 0.50 \% a la Facultad de Diseño, y el 0.25 \% restante hacía doble titulación (véase Figura 3).

Figura 2: Porcentaje de estudiantes por jornada

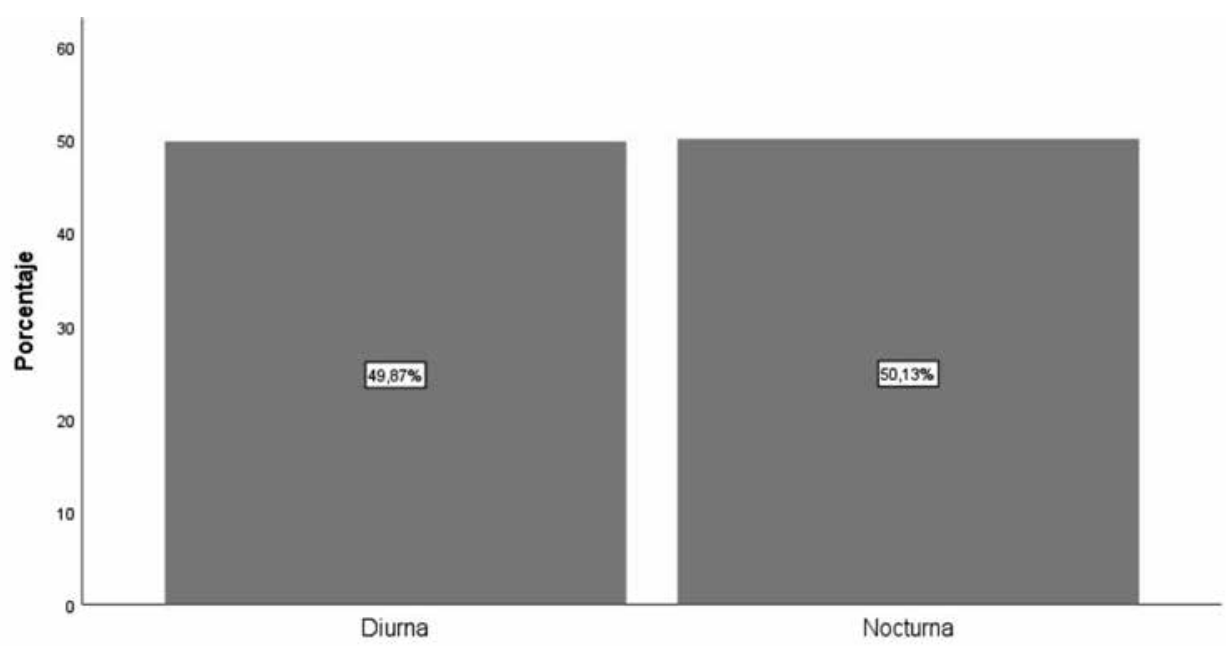


Figura 3: Porcentaje de estudiantes por facultad

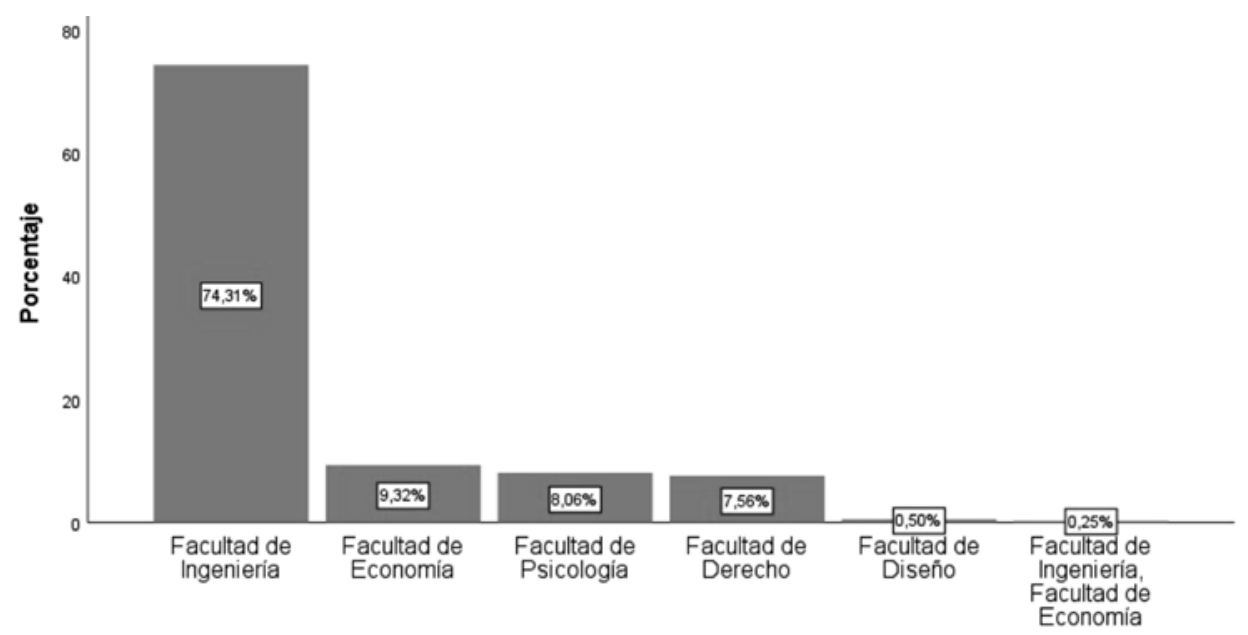

Adicional a esto, se encontró que los estudiantes encuestados tenían una edad promedio de 21.33 años, que el 50 \% tenía una edad inferior a los 20 años, que el $25 \%$ de las edades más altas estaban por encima de los 23 años, y que el $25 \%$ de las edades más bajas se encontraban por debajo de los 19 años. La variable edad presentó una dispersión de 3.947 años, en donde la edad mínima fue de 16 años y la máxima de 45 años (véase Figura 4).

Figura 4: Edad

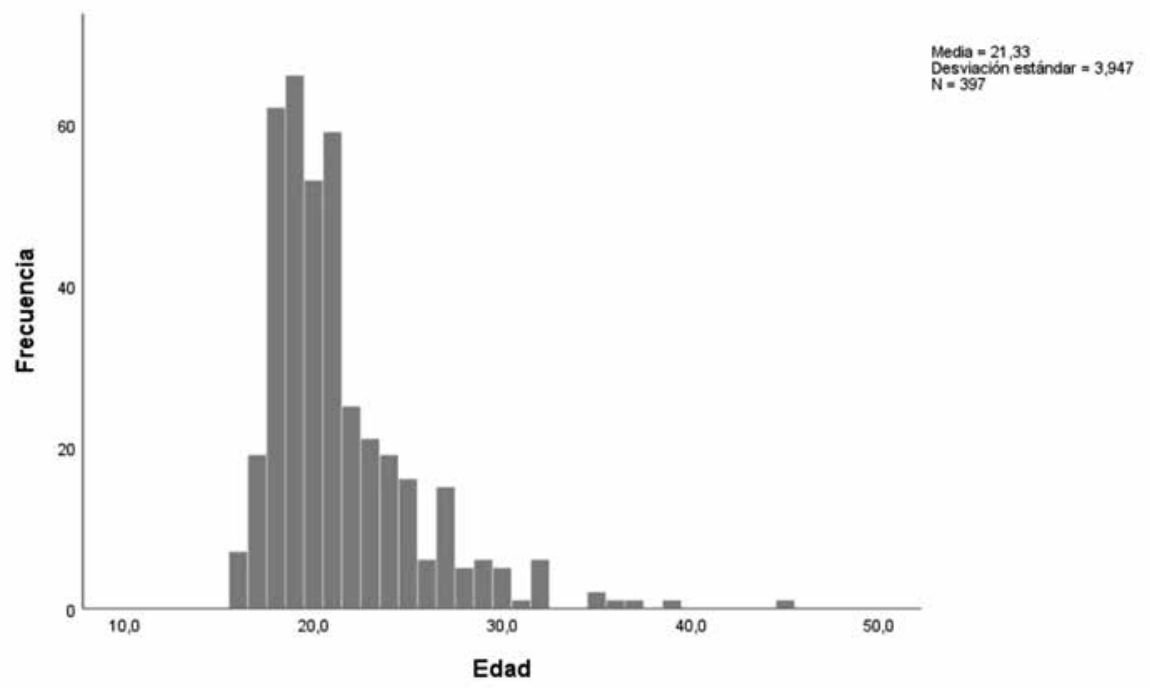


Ahora bien, con la aplicación del instrumento de recolección de la información, los resultados obtenidos en cada uno de los ítems se sistematizó y graficó, tal como se muestra en las Figuras 5-14.

Figura 5: Ítem 1. Se ha cumplido con los horarios de las sesiones de clases

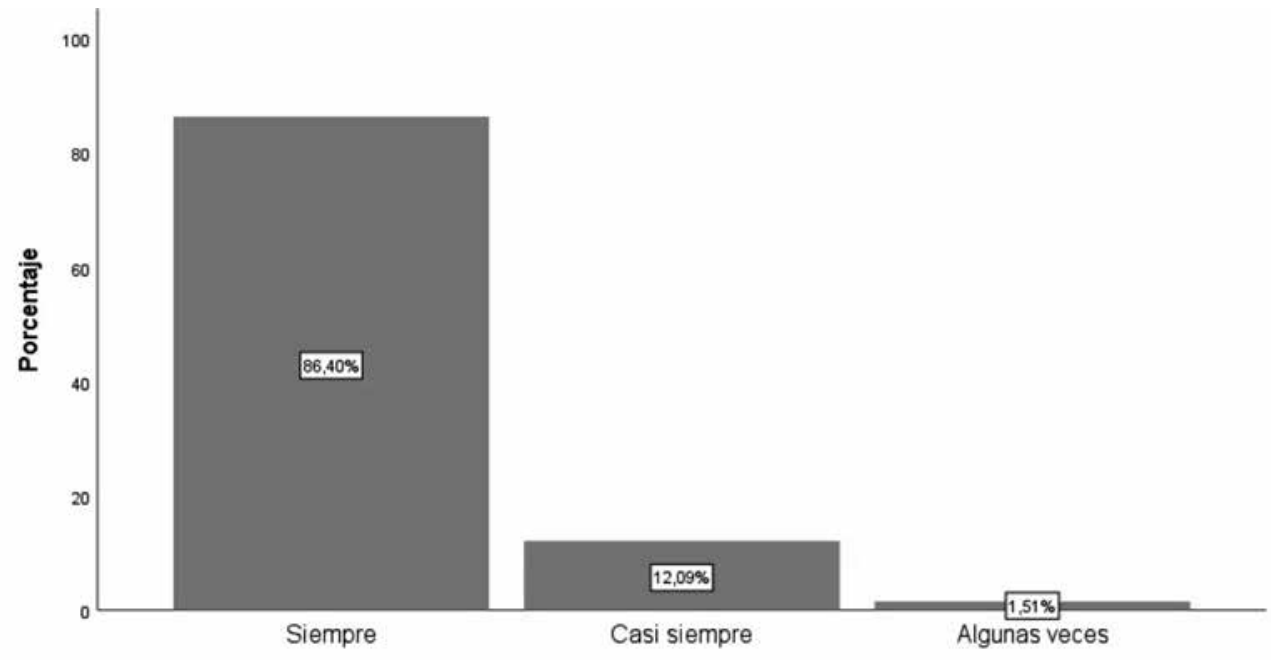

Figura 6: Ítem 2. La metodología ha permitido la construcción de conocimientos

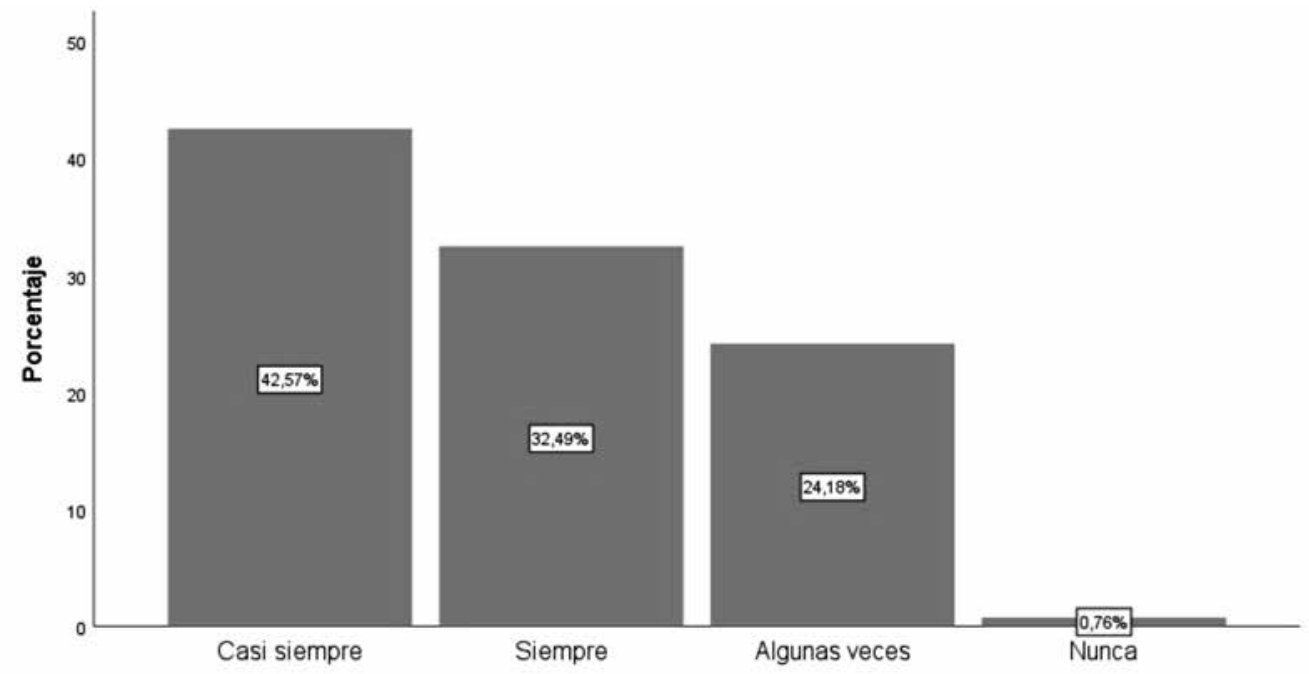


Figura 7: Ítem 3. Los contenidos programáticos se han presentado de manera adecuada, facilitando su aprendizaje

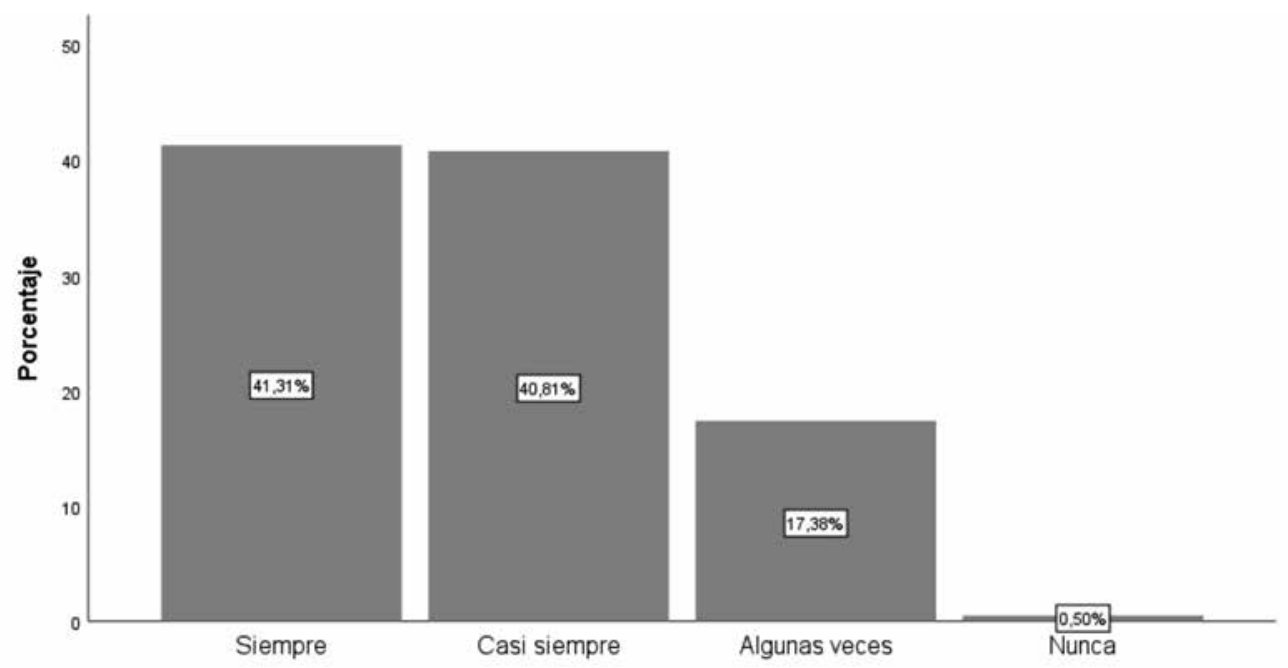

Figura 8: Ítem 4. Se han generado espacios de participación durante el desarrollo de las sesiones

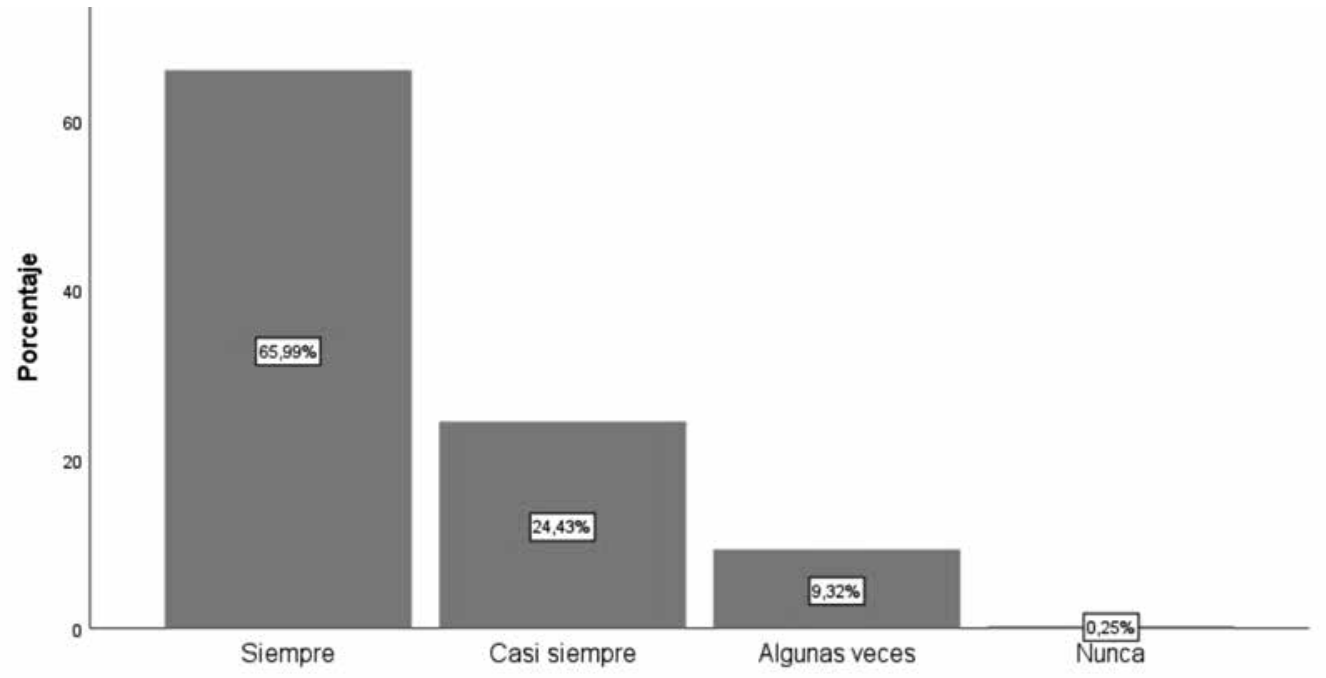


Figura 9: Ítem 5. Se han resuelto las dudas en las sesiones de clase o en su defecto en las tutorías y atención a estudiantes

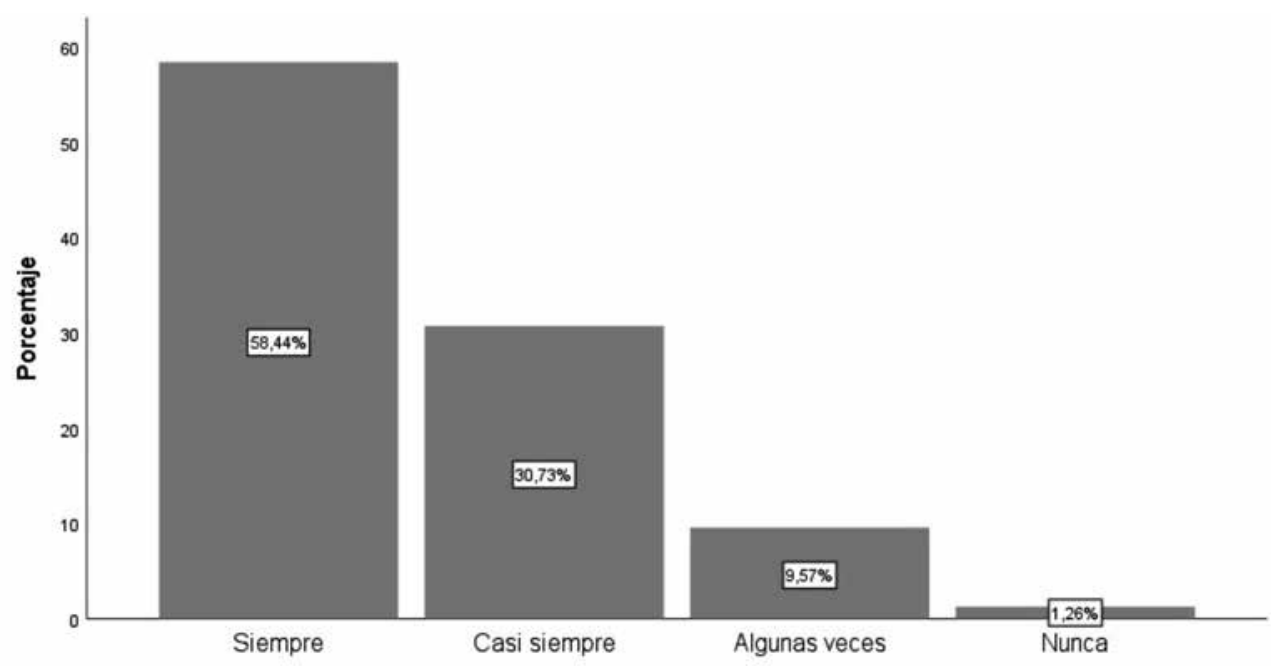

Figura 10: Ítem 6. Se ha hecho uso de diferentes recursos tecnológicos que facilitan el aprendizaje

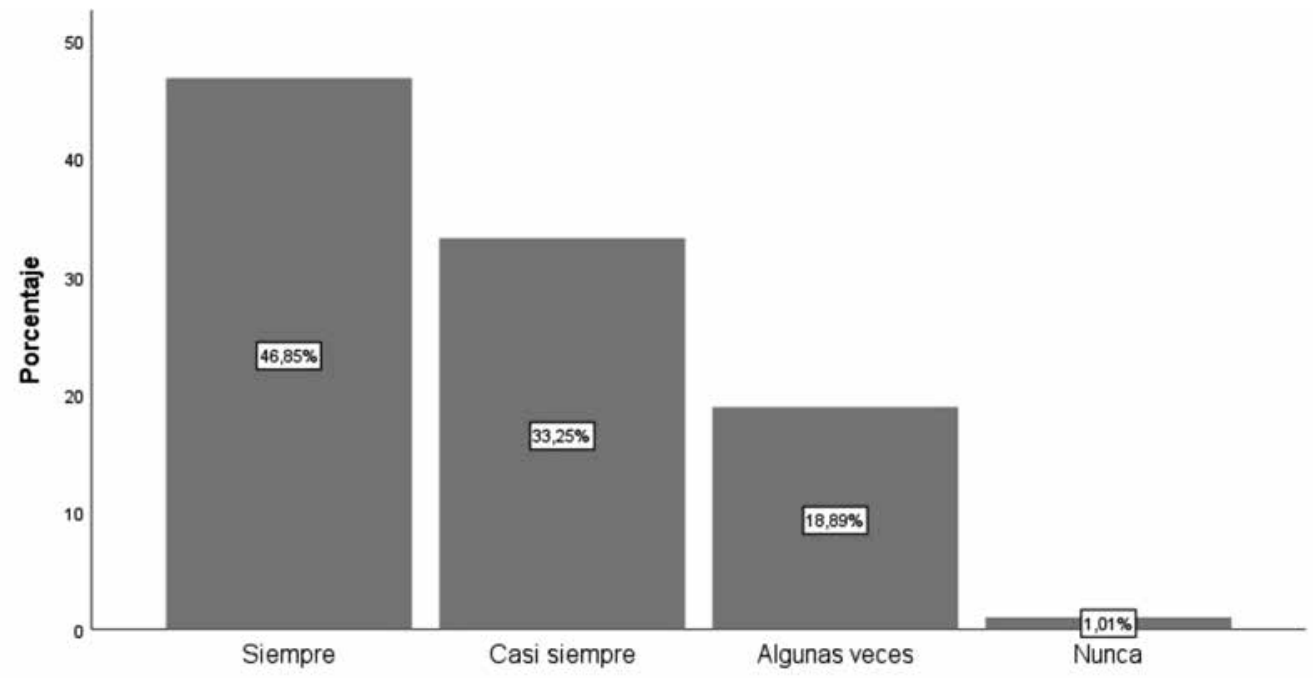


Figura 11: Ítem 7. Los valores propios de la educación y de la Universidad Católica se ven reflejados en las sesiones de clase

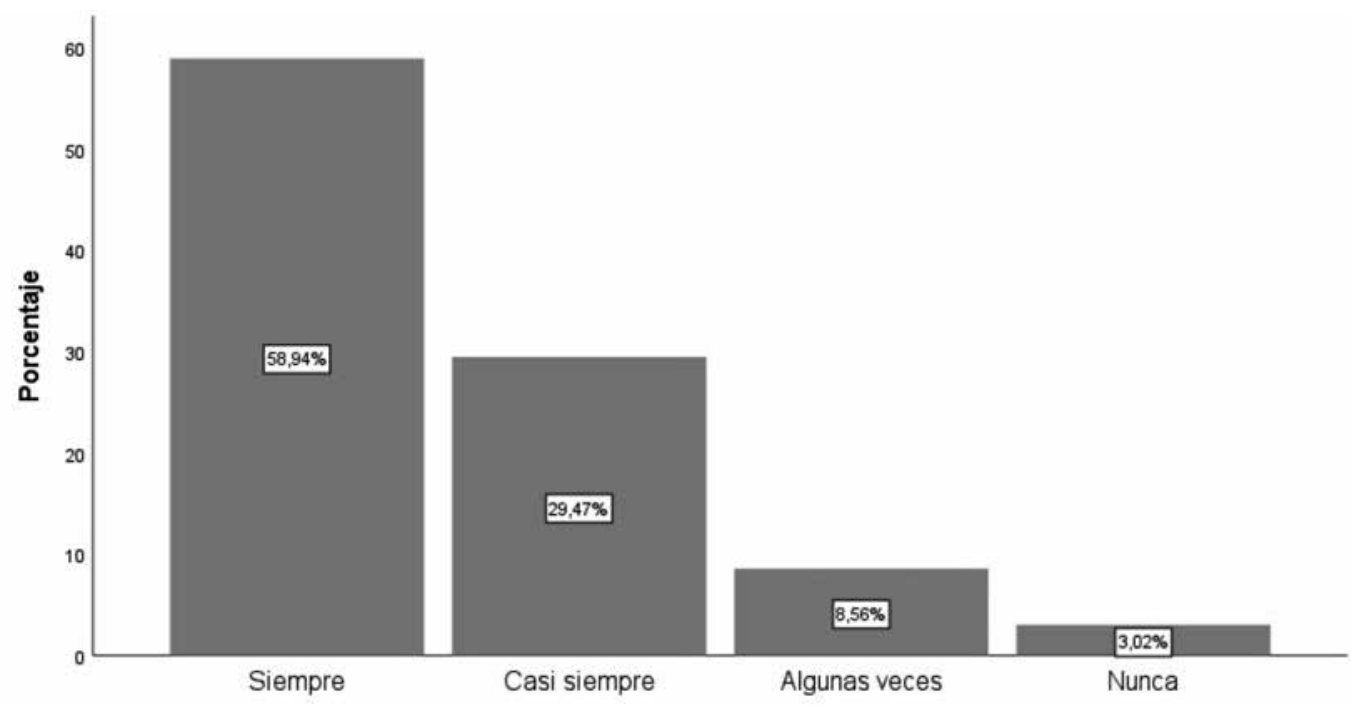

Figura 12: Ítem 8. Se hace uso de los recursos del AvA en las sesiones de clase

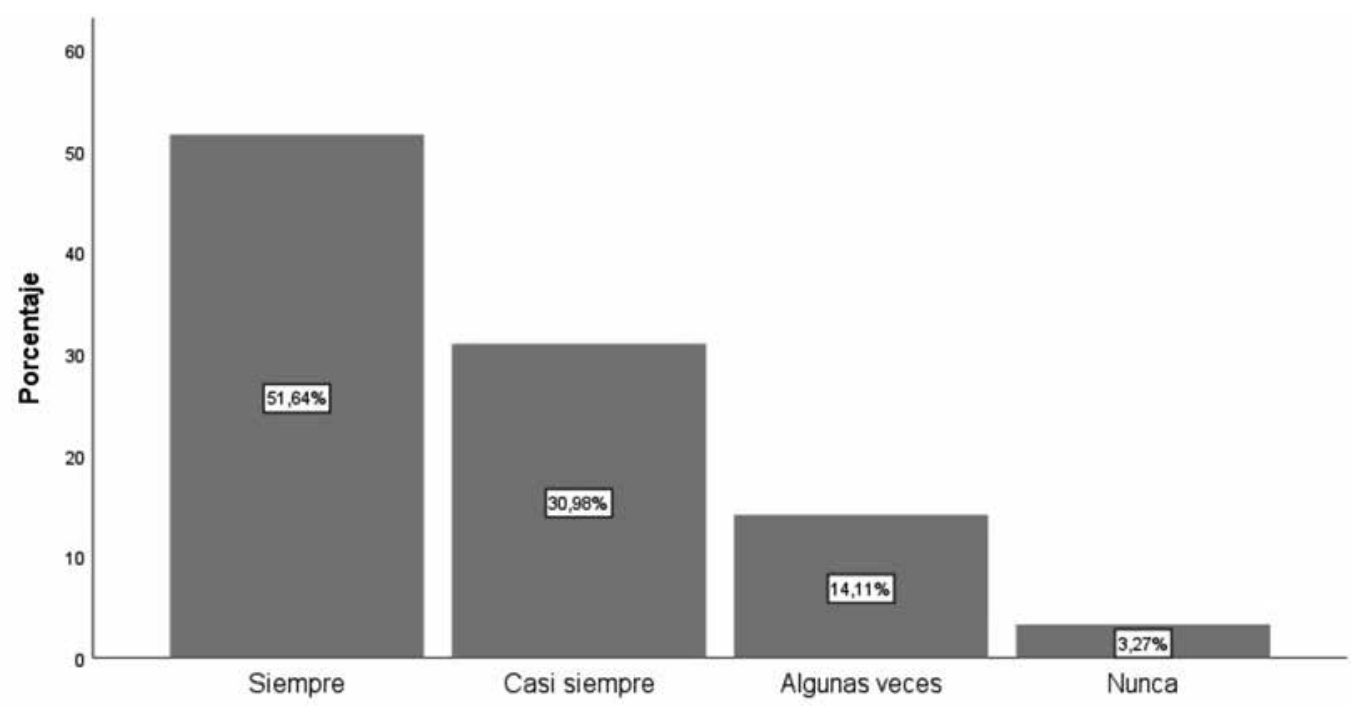


Figura 13. Ítem 9. La comunicación ha sido eficiente entre el docente y el estudiante a través de las diferentes plataformas, AVA y correo electrónico.

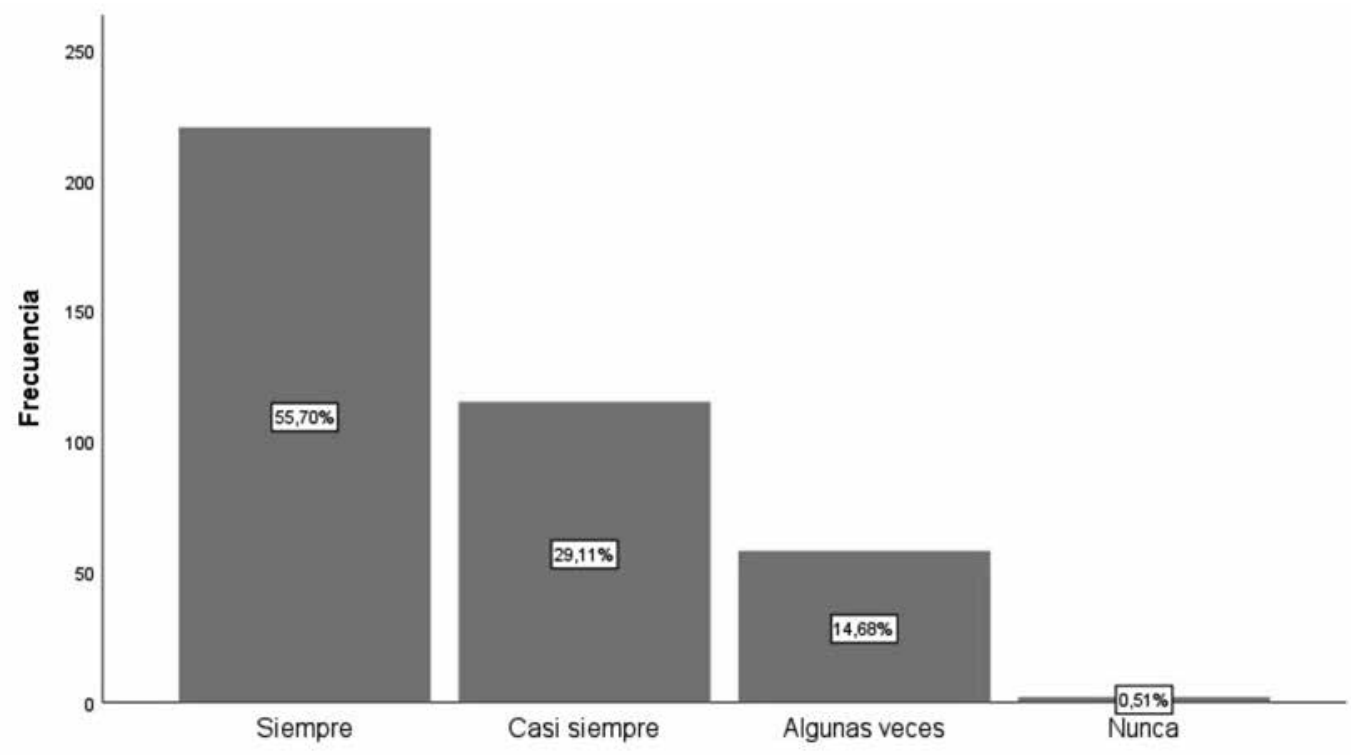

Figura 14: Ítem 10. Las evaluaciones realizadas son coherentes con el desarrollo de los contenidos programáticos en las sesiones remotas

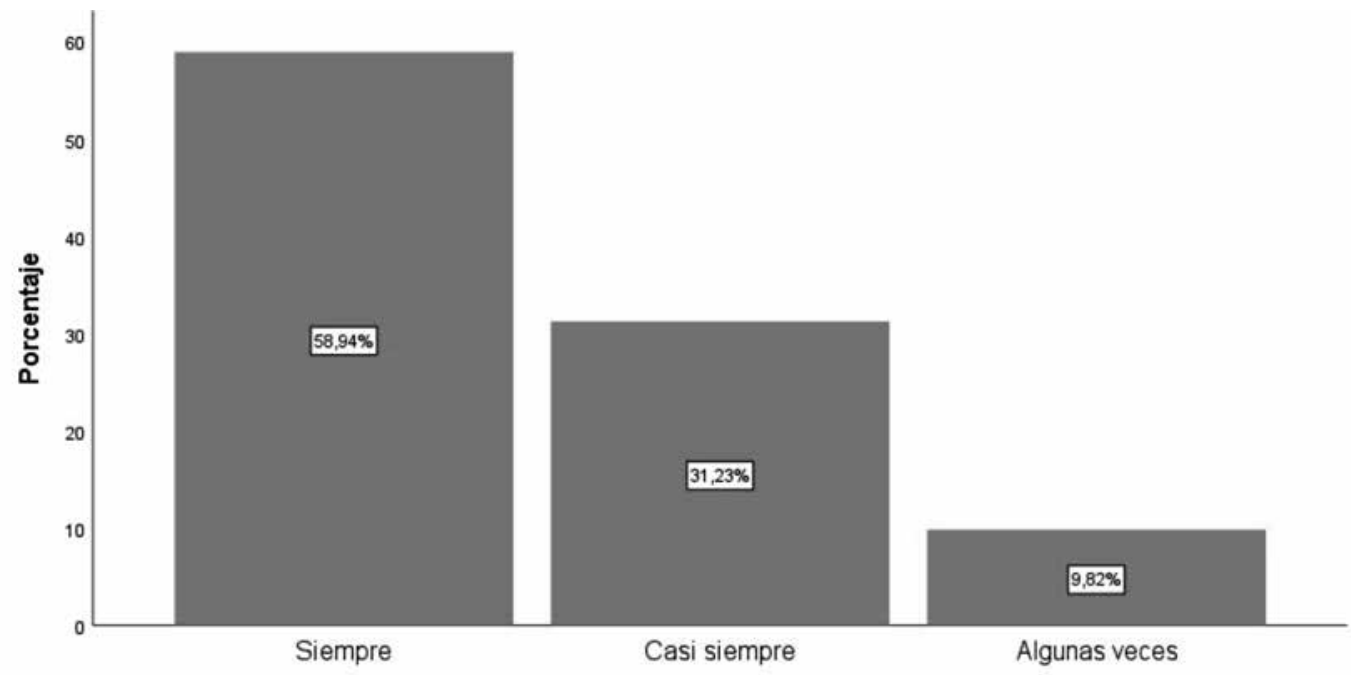


Como se puede observar, la percepción del Departamento, a pocas semanas de ser acatada la directriz presidencial de cuarentena a nivel nacional, fue muy favorable, ya que todos los ítems fueron evaluados positivamente ("Siempre" y "Casi siempre") en más de un 70 \%.

Sin embargo, para el Departamento era muy importante continuar registrando la respuesta de más estudiantes, razón por la cual se dejó abierta la posibilidad de que quienes no lo habían diligenciado pudieran responder el instrumento hasta terminar el semestre. Al finalizar este periodo, se obtuvo un total de 577 registros, cuyos resultados se pueden observar en la Tabla 1.

Tabla 1: Resultados de la encuesta al finalizar el trimestre

\begin{tabular}{|l|c|c|c|c|c|}
\hline \multicolumn{1}{|c|}{ Ítems } & $\mathrm{N}$ & Mínimo & Máximo & Media & $\mathrm{DE}$ \\
\hline $\begin{array}{l}\text { 1. Se ha cumplido con los horarios de las sesiones } \\
\text { de clases. }\end{array}$ & 577 & 2 & 4 & 3.82 & 0.429 \\
\hline $\begin{array}{l}\text { 2. La metodología ha permitido la construcción de } \\
\text { conocimientos. }\end{array}$ & 577 & 1 & 4 & 3.04 & 0.751 \\
\hline $\begin{array}{l}\text { 3. Los contenidos programáticos se han presentado } \\
\text { de manera adecuada, facilitando su aprendizaje. }\end{array}$ & 577 & 1 & 4 & 3.23 & 0.727 \\
\hline $\begin{array}{l}\text { 4. Se han generado espacios de participación durante } \\
\text { el desarrollo de las sesiones. }\end{array}$ & 577 & 1 & 4 & 3.52 & 0.679 \\
\hline $\begin{array}{l}\text { 5. Se han resuelto las dudas en las sesiones de clase o } \\
\text { en su defecto en las tutorías y atención a estudiantes }\end{array}$ & 577 & 1 & 4 & 3.43 & 0.744 \\
\hline $\begin{array}{l}\text { 6. Se ha hecho uso de diferentes recursos tecnológi- } \\
\text { cos que facilitan el aprendizaje. }\end{array}$ & 577 & 1 & 4 & 3.24 & 0.805 \\
\hline $\begin{array}{l}\text { 7. Los valores propios de la educación y de la Uni- } \\
\text { versidad Católica se ven reflejados en las sesiones } \\
\text { de clase. }\end{array}$ & 577 & 1 & 4 & 3.37 & 0.785 \\
\hline $\begin{array}{l}\text { 8. Se hace uso de los recursos del Ava en las sesiones } \\
\text { de clase. }\end{array}$ & 577 & 1 & 4 & 3.33 & 0.803 \\
\hline $\begin{array}{l}\text { 9. La comunicación ha sido eficiente entre el docente } \\
\text { y el estudiante a través de las diferentes plataformas, } \\
\text { Ava y correo electrónico. }\end{array}$ & 577 & 1 & 4 & 3.37 & 0.764 \\
\hline $\begin{array}{l}\text { 10. Las evaluaciones realizadas son coherentes con } \\
\text { el desarrollo de los contenidos programáticos en las } \\
\text { sesiones remotas. }\end{array}$ & 577 & 1 & 4 & 3.5 & 0.672 \\
\hline N válido (por lista) & 577 & & & & \\
\hline
\end{tabular}

Nota. Elaboración propia. 
Tras realizar el correspondiente análisis estadístico de los resultados obtenidos en cada uno de los ítems evaluados en el periodo 2020-1, se puede observar que el ítem con promedio más bajo es el que refiere a que "La metodología ha permitido la construcción de conocimientos" (ítem 2), con 3.04, seguido por el que señala que "Se ha hecho uso de diferentes recursos tecnológicos que facilitan el aprendizaje" (ítem 6), con 3.24, que a su vez presentó la mayor variabilidad, con 0.805 .

El perfil de respuestas de los estudiantes tras finalizar el semestre 2020-1 se puede encontrar en la Figura 15.

Figura 15: Perfil de respuestas estudiantes 2020-1

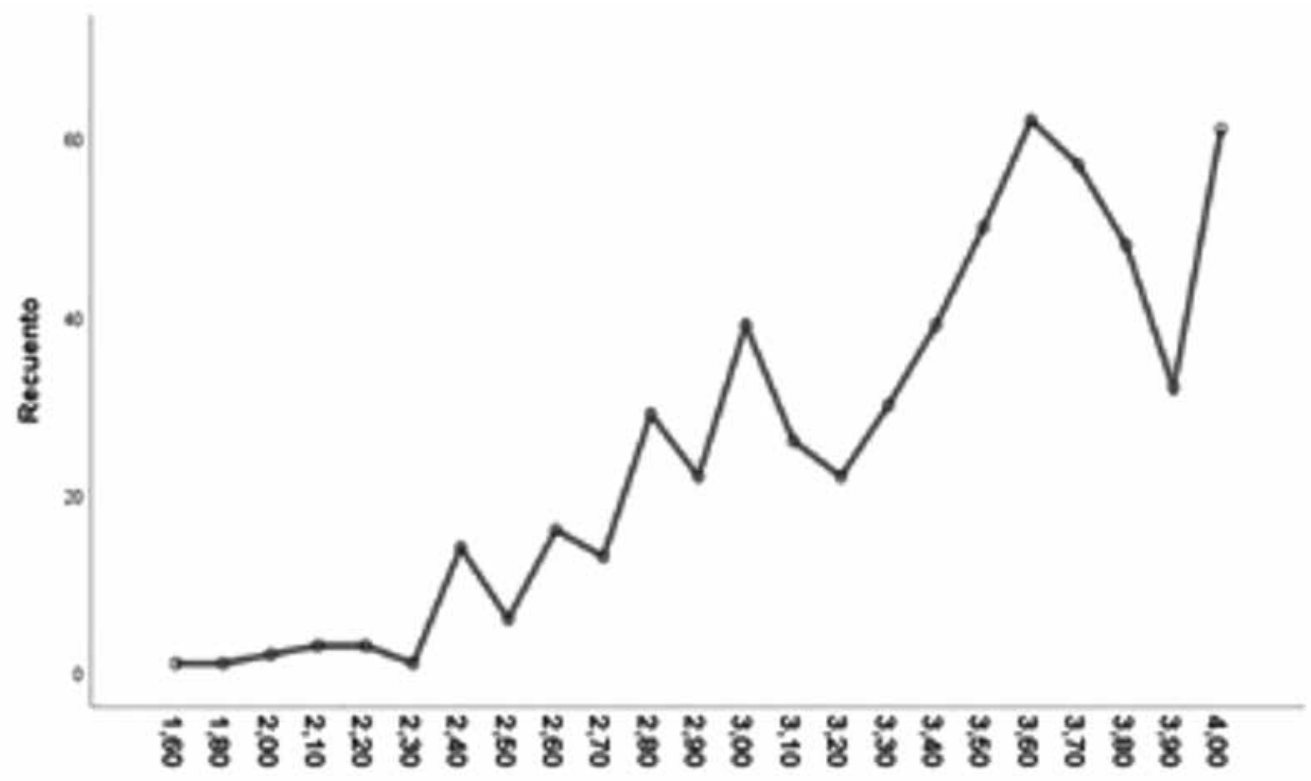

Nota. Elaboración propia.

Posteriormente, el mismo instrumento se aplicó a los docentes en el periodo 2020-1, y en su caracterización se encontró que el $64.4 \%$ de docentes del Departamento eran hombres, mientras que el $35.6 \%$ eran mujeres; que el $31.58 \%$ era de la jornada diurna, el $18.42 \%$ de la nocturna y el $50 \%$ de las dos jornadas; y que el $5.26 \%$ tenía asignaciones de una sola asignatura, el $21.05 \%$ de dos asignaturas, el $36.84 \%$ de tres asignaturas, y el $36.84 \%$ de más de tres asignaturas. El perfil de respuestas de los docentes tras finalizar el semestre 2020-1 se puede encontrar en la Figura 16. 
Figura 16: Perfil de respuestas de los docentes

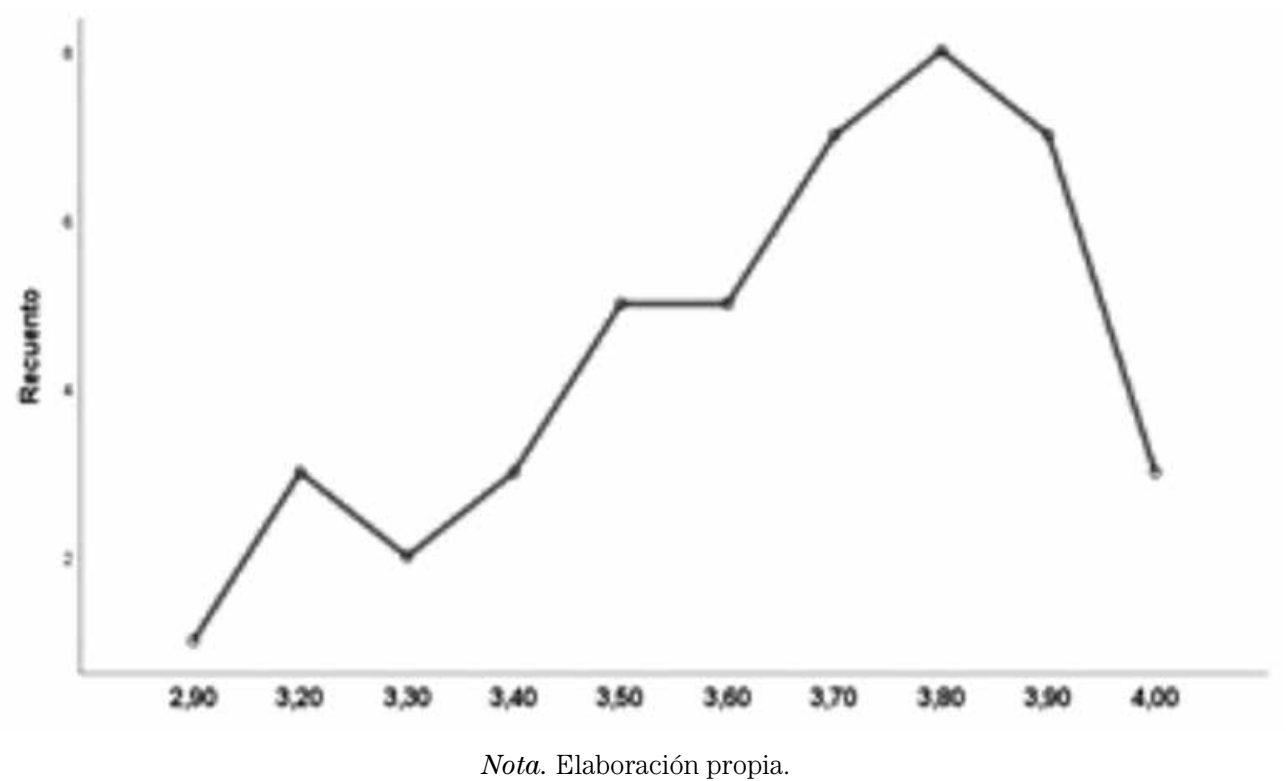

En particular, en los perfiles de respuesta se puede observar que los promedios obtenidos por cada docente para el periodo 2020-1 oscilaron entre 2.90 a 4.0, es decir, que la gran mayoría calificaron positivamente los ítems, con "Siempre" y "Casi siempre" en la mayoría de ellos.

Por otra parte, teniendo en cuenta la contingencia planteada por el COVID-19, se hizo necesario conocer, mediante un sondeo aplicado a los docentes, las diferentes estrategias que se estaban aplicando para evidenciar el aprendizaje en los estudiantes (véase Figura 17). En particular, se encontró que la estrategia más implementada fue el desarrollo de talleres, y que la menos utilizada a mediados del inicio de la pandemia fue la implementación de foros y cuestionarios en plataformas diferentes a Moodle. 
Figura 17: Estrategias de evaluación aplicadas en clases remotas

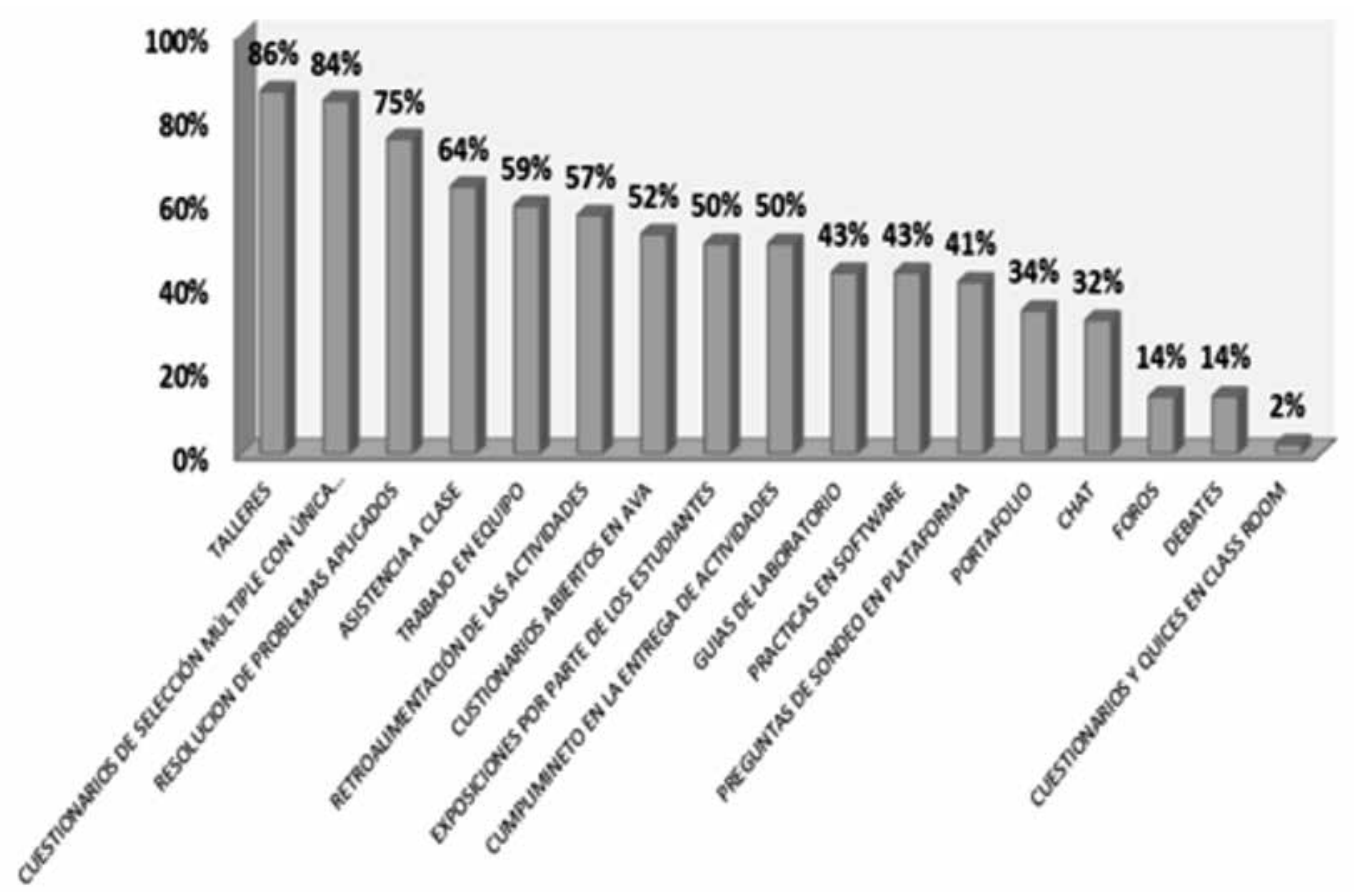

\section{Discusión de los resultados}

Si bien nos encontramos con sesiones de clases remotas que se ejecutaban únicamente adecuando el monitor del computador, de tal manera que los estudiantes tuvieran contacto visual con un tablero en acrílico sobre el cual el profesor emulaba el desarrollo de la clase presencial tradicional, fueron más los profesores que — comprometidos con garantizar la calidad de las sesiones de clase remotas - optimizaron sus espacios de trabajo personales en casa y buscaron poner en práctica todo tipo de recursos tecnológicos a su disposición. Así, el marcador fue reemplazado por el lápiz electrónico y por las tabletas digitalizadoras, y el tablero tradicional por herramientas ofimáticas como OneNote, PowerPoint o tableros digitales como Idroo. Los profesores no tardaron mucho en reconocer las ventajas inherentes que la transición del modelo de enseñanza presencial al modelo de enseñanza sincrónica remota traía consigo.

La posibilidad que tenían los ingenieros, economistas y psicólogos en formación de volver sobre las notas de clase desarrolladas por el mismo docente les permitía centrar su atención 
en las particularidades y en los detalles de las explicaciones hechas por su profesor, esto gracias al hecho de poder grabar las clases y que estas, a su vez, se convirtieran en insumo de consulta, revisión y aclaración de dudas, así como de material de apoyo para los procesos de evaluación adelantados en esta modalidad.

Además, se empezaron a generar hábitos — como la socialización de las percepciones y sensaciones que nos venían dejando las primeras semanas de clases remotas- en las reuniones de área y en los comités curriculares posteriores — resultados preliminares de la aplicación del instrumento a estudiantes y profesores-, lo que permitió evaluar, retroalimentar y ajustar el desarrollo de las sesiones posteriores, así como "pilotar" diferentes modelos y estrategias - como recursos y herramientas tecnológicas de acceso libre- que tenían como fin optimizar las clases y, por ende, hacer que fueran más exitosas y de mayor calidad.

Recogiendo y sistematizando toda esta información, la coordinación curricular, junto con la dirección del Departamento de Ciencias Básicas, ajustó la Ruta metodológica institucional, en la cual se elaboró una serie de recomendaciones para optimizar el tiempo y los recursos durante las clases. Institucionalmente hablando, se indicó que, en todas las sesiones de clase, los docentes debían identificar y plantear objetivos de aprendizaje, centrar las explicaciones en los temas fundamentales de la formación del profesional particular de los estudiantes, y, entre otras, optimizar la interacción y participación de los estudiantes con actividades diferentes a las videoconferencias - por ejemplo, talleres, trabajos en grupo, foros, y haciendo uso de recursos como Padlet, Mindmeister, Symbaloo, etc.- .

Metodológicamente, se direccionó la práctica docente hacia el uso de ejemplos contextualizados, aplicados, prácticos y actuales, y se tuvo siempre como enfoque la enseñanza en la metodología para acompañar a los estudiantes en la solución de problemas -lectura, interpretación, representación, planeación y solución-.

Además, con el paso de las sesiones de clase, tuvimos la posibilidad de implementar las actividades diseñadas en la fase de formación, como ocurrió con las prácticas de laboratorios en los cursos de las áreas de química, física y estadística.

Finalmente, es importante resaltar que el desarrollo de las sesiones de clases remotas fue incluso probado en espacios académicos interculturales, en los que ingenieros y economistas en formación de universidades mexicanas y argentinas reconocieron posibilidades que enriquecieron el desarrollo de dichas sesiones. 


\section{Algunas consideraciones}

Una vez terminadas las fases de identificación y de formación, y tras lograr que todos los cursos programados para el periodo académico 2020-1 transitaran del modelo presencial al remoto, reconocimos diferentes caminos sobre los cuales los docentes del Departamento de Ciencias Básicas pudieron interpretar y ajustar el desarrollo de sus prácticas docentes —evidentemente, condicionados por las posibilidades de acceso a herramientas tecnológicas-, de manera que verdaderamente les permitieran poner en práctica todo lo aprendido.

Por otro lado, los instrumentos de percepción tanto de estudiantes como de docentes se convirtieron en un recurso para la transformación constante y permanente de la aplicación de esta metodología, ya que su evaluación periódica permitió la ejecución de acciones correctivas o que potenciaran el proceso de enseñanza que se venía desarrollando en el Departamento de Ciencias Básicas de la Universidad Católica de Colombia.

Así, se podría afirmar que a pesar de que la transición de las clases presenciales a clases remotas mediadas por las TIC ha sido uno de los cambios mas bruscos, acelerados y más que obligantes para el sistema educativo, esto supuso develar una realidad enmascarada de "buenas prácticas" en un sistema principalmente tradicional. Aunque no estamos criticando este modelo — todo lo contrario-, sí afirmamos que fue necesaria una pandemia para que la formación docente, los procesos de enseñanza y aprendizaje, y en general todo el sistema educativo se transformara, movilizara y se adaptara a estas nuevas realidades. Con ello, fue posible establecer, como se evidencia en lo resultados, que no es apenas el salón de clase lo que incide en la percepción tanto de docentes como de estudiantes, sino que existen tantas otras variables que, hoy por hoy, adquieren relevancia y determinan el norte hacia donde debe dirigirse la educación.

\section{Agradecimientos}

Este capitulo se ha logrado gracias al empeño de la Universidad Católica de Colombia, el Departamento de Ciencias Básicas de esta institución, y la red de Departamentos de Ciencias Básicas, quienes han aunado sus voluntades por incidir en las prácticas docentes universitarias, desde esfuerzos mancomunados en torno a inquietudes referentes a los procesos de enseñanza y aprendizaje, la formación de profesores y la deserción o abandono estudiantil tanto a nivel universitario como, particularmente, en la educación en ciencias. 


\section{Referencias}

Barbera, E., \& Abadía, A. (2005). Hacia el aula virtual: Actividades de Enseñanza y Aprendizaje en Red. Revista Iberoamericana de Educación, 36 (9). https://rieoei.org/RIE/article/view/2769

Decreto 1278 de junio 19 de 2002. Por el cual se expide el Estatuto de Profesionalización Docente. Ministerio de Educación Nacional https://www.mineducacion.gov.co/1621/articles-86102_archivo_pdf.pdf

Garay, F., \& Mejía, S. (2020). Elementos identitarios de las prácticas de los docentes universitarios de ciencias básicas: diseño y validación de un instrumento sobre identidad docente. 4 Encuentro de Ciencias Básicas: Las ciencias básicas y los nuevos retos, Experiencias significativas en el aula y I Congreso internacional de Red de Departamentos de Ciencias Básicas: ciencia y tecnología 4(1), 125-135. https://dx.doi.org/10.14718/EncuentroCienc.Básicas.2020.4.10

García-Peñalvo, F., Corell, A., Abella-García, V., \& Grande, M. (2020). La evaluación online en la educación superior en tiempos de la COVID-19. Education in the Knowledge Society, 21, 26. https://doi. org/10.14201/eks.23086

Garritz, A. (2010). La enseñanza de la ciencia en una sociedad con incertidumbre y cambios acelerados. Enseñanza de las ciencias: revista de investigación y experiencias didácticas, 28(3), 315-326. https://raco.cat/index.php/Ensenanza/article/view/210803

Giannini, S. (2020). COVID-19 y educación superior: De los efectos inmediatos al día después. UNESCO. http://www.iesalc.unesco.org/wp-content/uploads/2020/05/COVID-19-ES-130520.pdf

Oviedo, H. C., \& Campo, A. (2005). Aproximación al uso del coeficiente alfa de Cronbach. Revista Colombiana de Psiquiatría, 34(4), 572-580. http://www.scielo.org.co/scielo. php?script=sci_arttext\&pid=S0034-74502005000400009\&lng=en\&tlng=es

UNESCO. (2008). Estándares de competencias en TIC para docentes. https://eduteka.icesi.edu.co/ pdfdir/UNESCOEstandaresDocentes.pdf 